\title{
What is going on with Adenosine?
}

\author{
Pilar Egea-Serrano ${ }^{1 *}$, Salvador Montalbán-Larrea ${ }^{1}$, Juan M Lacal-Peña ${ }^{2}$ and Alfredo Vidal-García ${ }^{1}$ \\ ${ }^{1}$ Cardiology Department, Hospital General Universitario Rafael Méndez, Spain \\ ${ }^{2}$ Cardiology Department, Hospital General Jerez, Spain
}

Submission: August 17, 2017; Published: August 29, 2017

*Corresponding author: Pilar Egea Serrano, Cardiology Department, Hospital General Universitario Rafael Méndez, Lorca Carretera Nacional 340, Km 589.30817, Lorca, Spain, Email: p.egeaserrano@gmail.com

Keywords: Adenosine; Tachycardia; Paradoxical response

\section{Introduction}

Adenosine bolus administration is extremely valuable in the first approach to narrow-QRS tachycardia. We present two cases in which this strategy leaded to an unexpected effect. We focus

on the importance of knowing this effect of the adenosine in this setting so that the maneuver is performed in an appropriate place and carried out by trained staff.

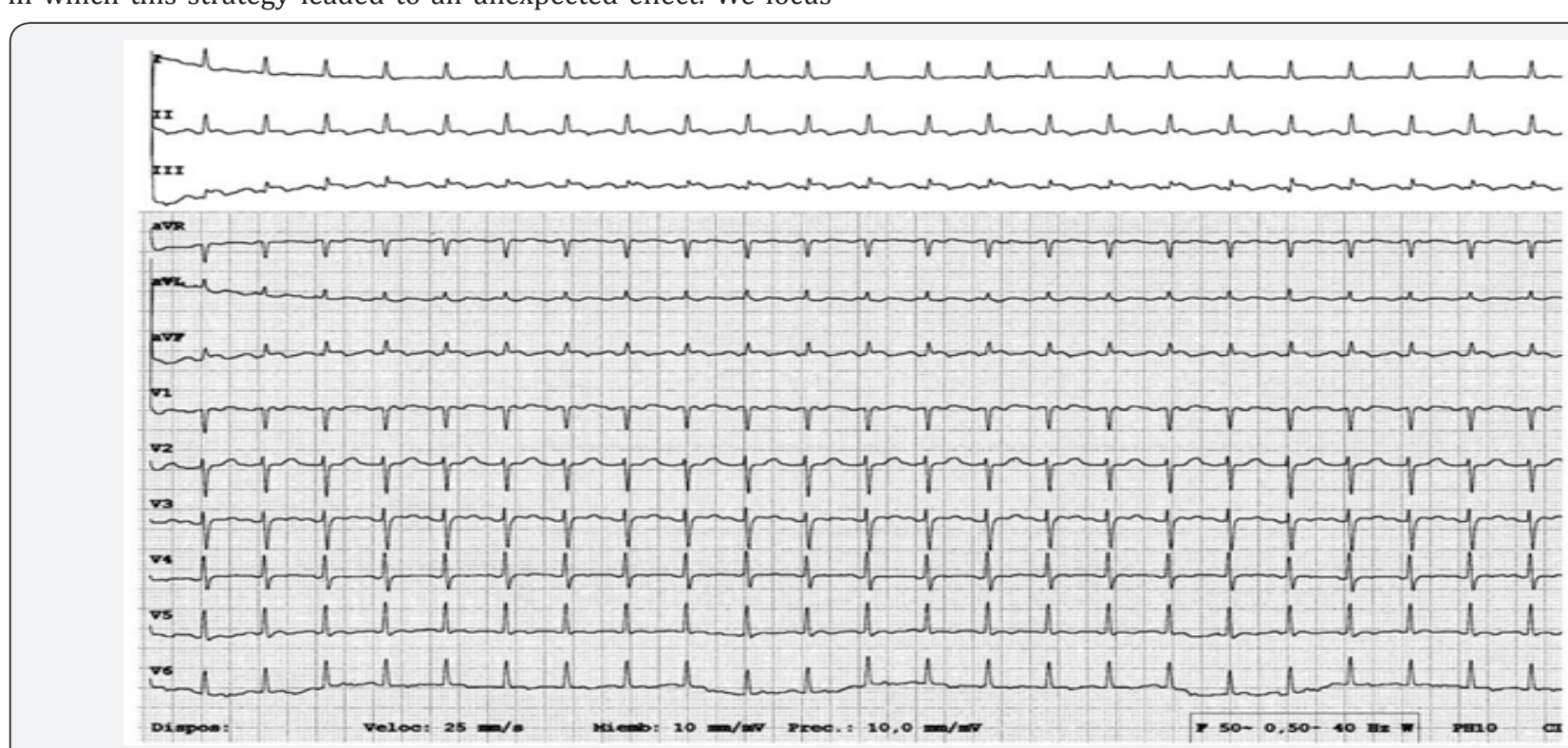

Figure 1: Regular narrow-QRS tachycardia.

\section{Case Report}

\section{Case A}

73-year-old lady with hypertension, diabetes and dyslipidemia referred progressive dyspnea for two months. On physical examination, no murmurs, arrhythmia or crackles were audible. Cardiomegaly was present on the x-ray chest. ECG is performed (Figure 1): narrow QRS tachycardia with low voltage. Then, a bolus of $6 \mathrm{mg}$ of adenosine is administered intravenously twice as a diagnostic and possibly therapeutic approach (Figure 2). With the first bolus, a wide-QRS non-sustained tachycardia (consistent with non-sustained ventricular tachycardia) is induced. Conversely, with the second bolus, the supraventricular tachycardia got more accelerated. The expected response to adenosine (which could be whether finishing the tachycardia or opening it) did not occur in any case. The auriculo-ventricular (AV) node did not get blocked so that neither a possible reentry tachycardia did not stop nor the auricular activity could not be seen ("open the tachycardia"). 


\section{Journal of Cardiology \& Cardiovascular Therapy}

Severe pericardial effusion was found on the echocardiogram although tamponade signs were not present. Because the patient was stable and the pericardial effusion did not compromise the haemodinamics, the heart rate was finally controlled after 300 milligrams of amiodarone: the ECG was consistent with atrial flutter (Figure 2). Pericardial effusion is drained percutaneously afterwards, heart rate control strategy is decided respecting atrial flutter (the patient did not suffer palpitations, there was not left ventricular systolic dysfunction, and on the other hand there were left atrial dilatation and underlying factors for relapse), and anticoagulation therapy was started according CHA2DS2VASc criteria. In the follow-up the patient did well: no specific cause for the pericardial effusion was found and heart rate control was achieved with a drug combination.

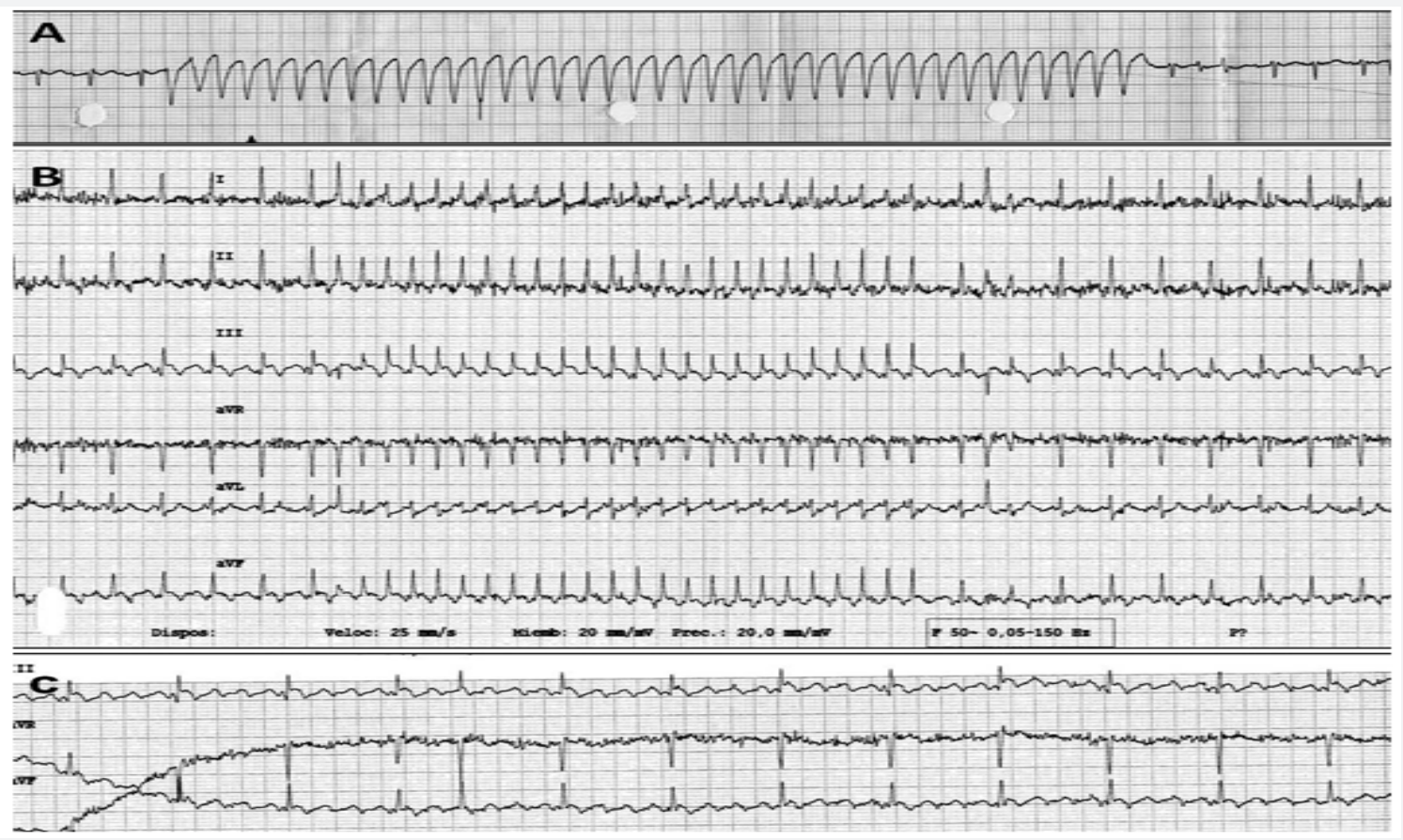

Figure 2: A) ECG strip with non-sustained venticular tachycardia. B) Supraventricular tachycardia accelerated up to 300 beats per minute after intravenous adenosine. C) Atrial flutter with heart rate within normal limits after amiodarone.

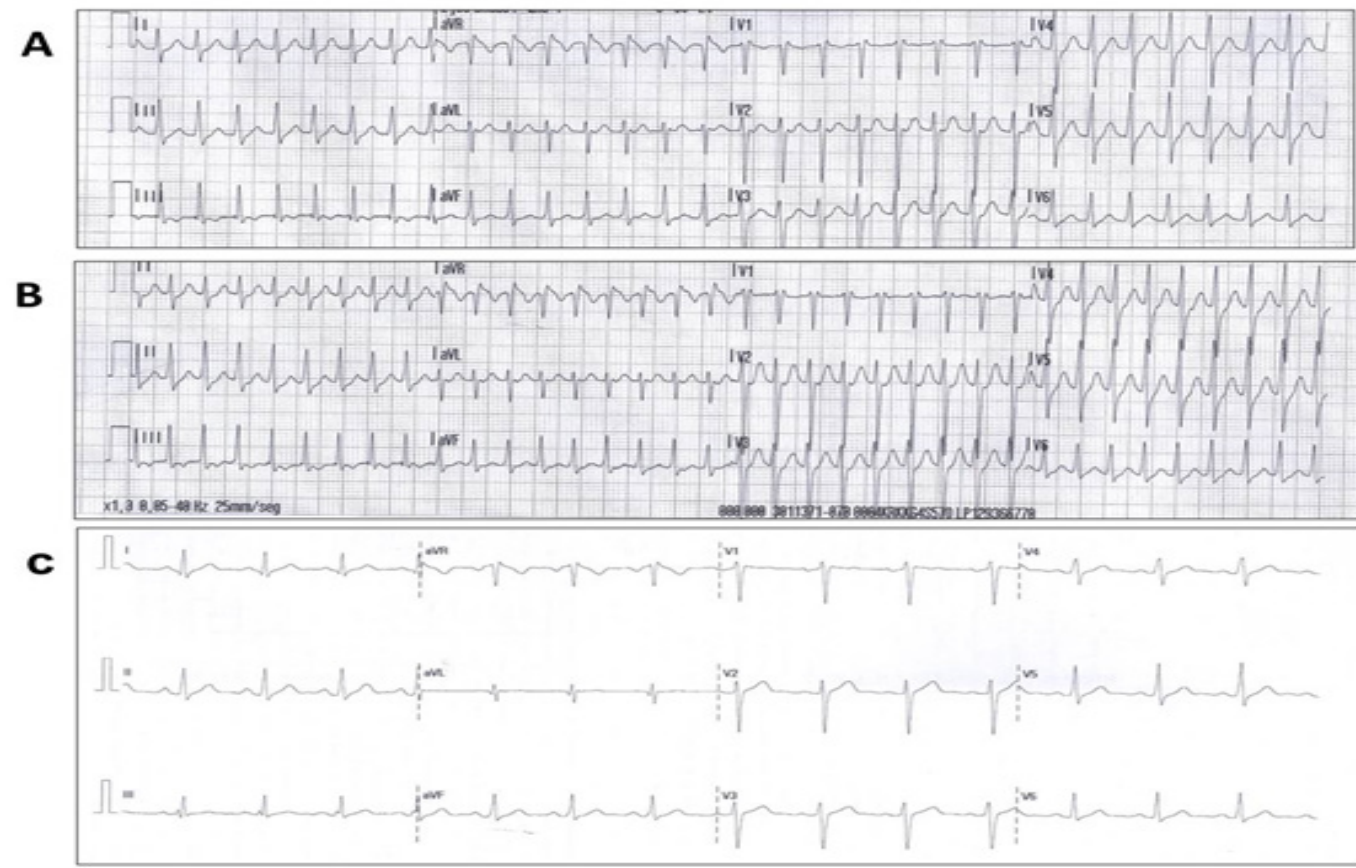

Figure 3: A) supraventricular tachycardia. B) Accelerated supraventricular tachycardia after adenosine administration. C) Basal ECG with short PR segment and delta wave in avF. 


\section{Case B}

37-year-old man with no relevant medical history was attended in the Emergency Room for palpitations. No other symptoms were present and he was haemodinamically stable. The initial ECG showed regular narrow QRS tachycardia at 190 beats per minute (Figure 3). After 6 milligrams of adenosine were run intravenously, the same morphology tachycardia went up to 220 beats per minute (Figure 3). A new bolus of 12 milligrams of adenosine finally subjugated the arrhythmia. Basal ECG revealed sinusal rhythm with a short PR segment and delta wave seen on aVF (Figure 3). Blood test and echocardiogram were within normal limits. The patient was sent to electrophysiology study.

\section{Discussion}

Both cases are aboutsupraventricular tachycardia: atrial flutter with a 2:1 conduction in case A and paroxysmal supraventricular tachycardia maybe due to hidden accessory pathway in case B. Adenosine administration not only firstly induced a non-sustained ventricular tachycardia in case $\mathrm{A}$ but also it fomented a more rapid conduction through AV node temporarily. This pro-arrhythmic effect of adenosine is uncommon and not widely known. It is addressed to a reflex catecholamine's discharge and to carotid chemoreceptors stimulation by sympathetic system. These effects lead to a higher conduction velocity through the AV node and they may also boost an increase in the ventricular automatism and so a ventricular tachycardia to appear (which also can degenerate to a torsades des pointes) [1-4].
Adenosine administration in the presence of tachycardia continues being extremely useful because it can help diagnose and it could be therapeutic. This drug has high efficacy and safety, and its side effects take a few seconds. The AV node is blocked by the drug and then the differential diagnosis of the tachycardia is set (whether the tachycardia depends on a re-entry or not) and therefore a specific treatment can be indicated, which occasionally implies a risky drug as the anticoagulation can be. These paradoxical chronotropic effects of the adenosine must be widely known but they do not contraindicate the manoeuvre per se. However, it is recommended to be performed by trained staff who would be prepared to act in case of complications would occur [2].

\section{References}

1. Brodsky MA, Allen BJ, Grimes JA, Gold C (1994) Enhanced atrioventricular conduction during atrial flutter after intravenous adenosine. N Engl J Med 330: 288-289.

2. Mallet ML (2004) Proarrhythmic effects of adenosine: a review of the literature. Emerg Med J 21(4): 408-410.

3. Brenes JA (2013) A caveat during adenosine challenge. Cardiovasc J 5(2): 206-207.

4. Rankin AC, Rae AP, Houston A (1993) Acceleration of ventricular response to atrial flutter after intravenous adenosine. Br Heart J 69(3): 263-265.

Your next submission with Juniper Publishers will reach you the below assets

- Quality Editorial service

- Swift Peer Review

- Reprints availability

- E-prints Service

- Manuscript Podcast for convenient understanding

- Global attainment for your research

- Manuscript accessibility in different formats

( Pdf, E-pub, Full Text, Audio)

- Unceasing customer service

Track the below URL for one-step submission https://juniperpublishers.com/online-submission.php 